\title{
Projetos Uniforms de Andrea Zittel: linhas de força e de resistência no dispositivo moda
}

Andrea Zittel's Uniforms projects: lines of force and resistance in the fashion dispositive

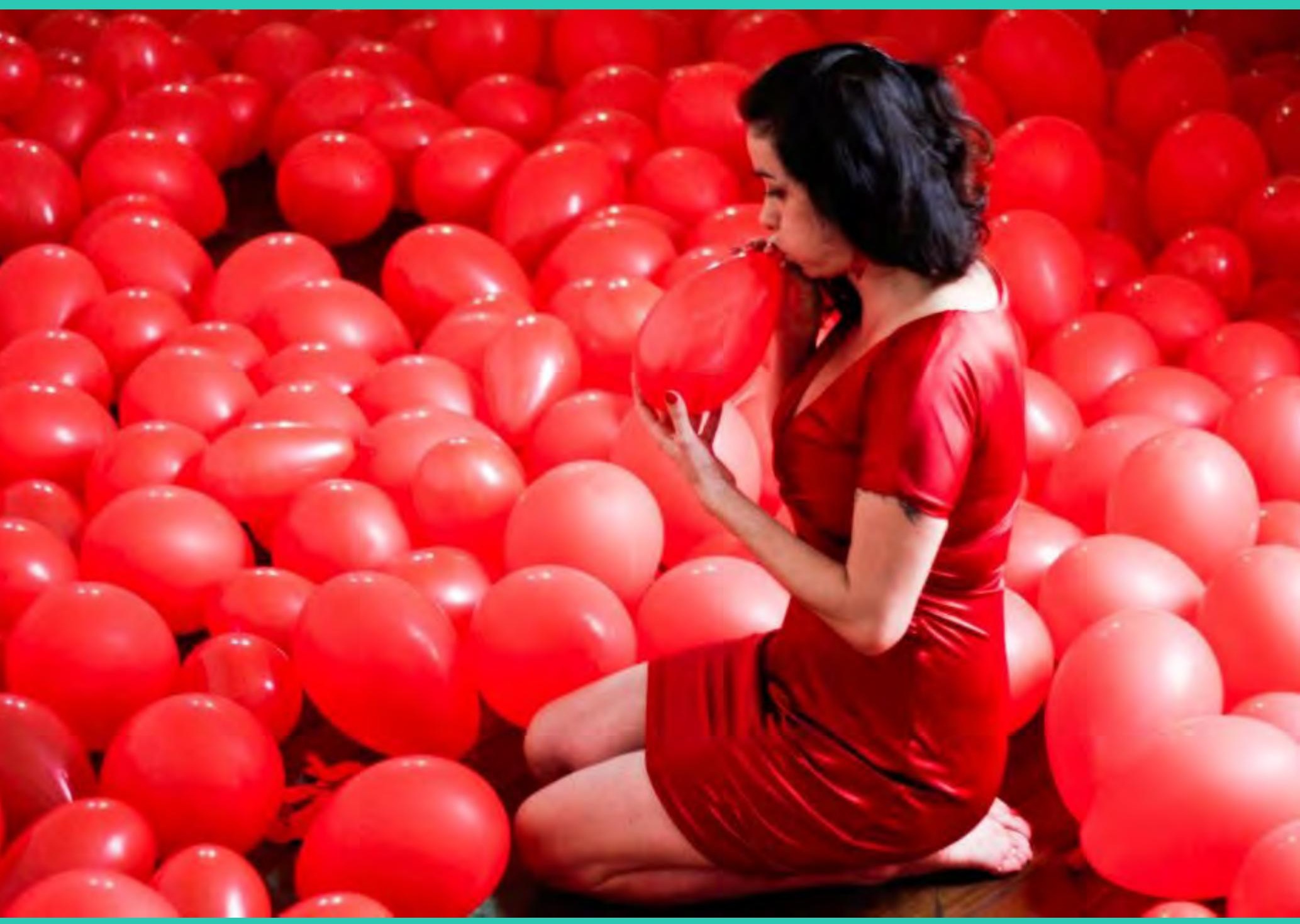




\section{Larissa Almada ${ }^{1}$}

ORCID: https://orcid.org/0000-0002-3149-2349

\section{Cristiane Mesquita}

ORCID: https://orcid.org/0000-0001-6860-0676

[resumo] Compreendendo a moda como um dos dispositivos que produzem modos de vida no contexto contemporâneo, este artigo apresenta os projetos Uniforms da artista americana Andrea Zittel, tomados como referências para problematizar os padrões do vestir, a efemeridade e o consumismo, considerados linhas de força no dispositivo moda. Inicialmente, é apresentada uma breve trajetória do vestuário na arte. Na sequência, é feito um panorama sobre Zittel e os projetos Uniforms, pontuando o trajeto da artista nessas proposições. Com base nos filósofos Gilles Lipovetsky e Lars Svendsen, apresenta-se uma visão teórica sobre linhas de força no dispositivo moda para observar discursos de moda veiculados em mídias impressas e digitais, que apontam sua ação na contemporaneidade. As criações de Zittel são consideradas linhas de resistência ao efeito hegemônico produzido pelo dispositivo de moda, contrariando regras e desafiando-o, propondo outros modos de vida que mostram diferentes perspectivas para lidar com o vestir.

\section{[palavras-chave] Projetos Uniforms. Andrea Zittel. Dispositivo moda.}

[abstract] Understanding fashion as one of the dispositives that produce lifestyles in the contemporary context, this article presents the Uniforms projects of the American artist Andrea Zittel, taken as references to problematize the patterns of dressing, ephemerality and consumerism, considered lines of force in the fashion dispositive. A brief trajectory of clothing in art is initially presented, followed by a panorama on Zittel and the Uniforms projects, punctuating the path of the artist in these propositions. From the philosophers Gilles Lipovetsky and Lars Svendsen, a theoretical vision on lines of force in the fashion dispositive is presented to observe fashion speeches in the printed and digital media, which point out its action in the contemporary world. Zittel's creations are considered lines of resistance to the hegemonic effect produced by the fashion dispositive, contradicting rules and challenging it, by proposing other ways of life that show different perspectives to deal with dressing.

[keywords] Uniforms projects. Andrea Zittel. Fashion dispositive.

Recebido em: 21-10-2019

Aprovado em: 20-03-2020

\footnotetext{
${ }^{1}$ Doutoranda em Design pela Universidade Anhembi Morumbi - SP. Docente dos bacharelados e Pós-Graduação em Design de Moda e Negócios da Moda da Universidade Anhembi Morumbi. E-mail: Larissa_almada@ yahoo.com.br. Lattes: http://lattes.cnpq.br/3002455792956445.

2 Pós-Doutorado em Artes pela Goldsmiths University of London. Docente do Programa de Pós-Graduação, Mestrado e Doutorado em Design da Universidade Anhembi Morumbi. E-mail: cfmesquita@anhembi.br. Lattes: http://lattes.cnpq.br/3922424679187086.
} 


\section{Introdução}

"Primeiro grande dispositivo a produzir social e regularmente a personalidade aparente, a moda estetizou e individualizou a vaidade humana, conseguiu fazer do superficial um instrumento de salvação, uma finalidade de existência" (LIPOVETSKY, 1989, p. 39). 0 filósofo francês Gilles Lipovetsky anuncia a moda como dispositivo capaz de produzir subjetividades por meio do vestir.

Nesse sentido, o vestuário está presente nos processos de subjetivação, possibilitando que os sujeitos se constituam. Muitas vezes, a vestimenta pode ser determinante tanto para a inserção social dos indivíduos - processo facilitado pela produção em escala de um mesmo modelo de roupa - quanto para a diferenciação entre os mesmos - viabilizada pela variedade de peças existentes.

Vale mencionar que a moda, considerando o setor do vestuário, aproxima-se das lógicas do design principalmente a partir das mudanças ocorridas na segunda metade do século XX, quando o fenômeno do prêt-à-porter - pronto para vestir - passa a dominar a criação e a produção nesse campo, fortalecendo questões como a fabricação de itens em escala industrial.

Pela perspectiva da produção de subjetividade engendrada por peças do vestuário, aqui a moda é tomada como dispositivo, desdobramento do conceito inscrito pelo filósofo francês Michel Foucault (1979) e articulado nos estudos do filósofo francês Gilles Deleuze (1999) e do filósofo italiano Giorgio Agamben (2009). Guardadas suas diferenças de abordagem, dispositivo pode ser entendido como uma rede heterogênea de práticas disciplinares e de controle, na qual se articulam discursos, regras, instituições. Suas tramas produzem modos de vida, formas de ver, sentir e existir. Seus componentes são linhas de forças que, sustentadas pelo par poder-saber, fazem esse dispositivo funcionar.

Uma das variáveis ativas no dispositivo moda são os manuais de estilo que enunciam padrões de vestir. Esses manuais, somados a outras diretrizes, como a reprodutibilidade de roupas em escala industrial, favorecem a lógica do efêmero e trabalham a favor do mercado da moda, que muda incessantemente esses padrões estimulando o consumo. Entre outras questões, essas linhas de força fomentam seu funcionamento e sua manutenção, atravessando modos de vida contemporâneos, pautados pelo desejo de novidades e de variações incessantes (ALMADA; MESQUITA, 2017).

Contudo, por entre linhas de força, em um dispositivo, sempre emergem linhas de resistência que trabalham nas transversais daquilo que é condicionado. As linhas de resistência no próprio campo ou em outros, em geral, colocam em questão os modos de funcionamento do próprio dispositivo.

Nesse contexto, este estudo problematiza as linhas de força atreladas ao dispositivo moda colocadas em questão a partir dos projetos Uniforms (1991-2014), da artista americana Andrea Zittel, que neste artigo são tomados como linhas de resistência. Vale mencionar que a arte enquanto ferramenta de criação "[...] provoca, instiga e estimula nossos sentidos descondicionando-os, isto é, retirando-os de uma ordem preestabelecida e sugerindo ampliadas possibilidades de viver e de se organizar no mundo" (CANTON, 2009, p. 12). Conforme Brandão (2000, s.p.), "a obra de arte é ato de resistência no sentido em que desobedece, ignora palavras de ordem." Assim, coloca em jogo o que está convencionado. 
Para este estudo, inicialmente, faz-se um breve panorama sobre Andrea Zittel e, em um segundo momento, apresentam-se os projetos Uniforms, elucidando o trajeto percorrido pela artista nessas proposições. A partir dos pensamentos de Gilles Lipovetsky e do filósofo norueguês Lars Svendsen, para além de discursos de moda veiculados em mídias impressas e digitais, o dispositivo moda é articulado.

Dessa maneira, este artigo procura contribuir com as áreas do Design de Moda e da Arte, por ampliar o repertório teórico e tecer transversalidades entre os campos em questão.

\section{0 vestuário como objeto de arte}

Desde o início do século XX, o campo da arte vem sendo fértil para proposições capazes de provocar o status quo de diversas áreas, inclusive o da própria arte (CANTON, 2009). A utilização de objetos não usuais desse terreno, como o vestuário, é tomada como um dos modos de fazer operar essas provocações e de problematizar o cotidiano.

Nesse sentido, o artista francês Marcel Duchamp (1887-1968) destaca-se. Precursor dos ready-mades ${ }^{3}$ (1912), Duchamp questionou o pensamento clássico da arte, ressignificando objetos do cotidiano (ARCHER, 2005). Artefatos advindos da indústria de bens de consumo ganharam o território das artes plásticas, tal como a roda de bicicleta montada sobre uma banqueta (Roda de Bicicleta - 1912) e o urinol (Fonte - 1917) assinado por R. Mutt ${ }^{4}$. Duchamp utilizou também vestimentas e o próprio corpo como obras. Travestido de Rrose Sélavy, figurava como modelo de produtos comerciais criados por ele mesmo, como o perfume Belle Haleine Eau de Voilette (1921). Por meio de roupas e outros produtos, Marcel Duchamp "[...] ridicularizava a cultura e a hipocrisia dos comportamentos convencionais" (COSTA, 2009, p. 47).

Vale ressaltar que Duchamp foi um expoente do Dadaísmo, movimento que, em 1916, emergiu contestando valores tradicionais consagrados pela sociedade. Porém quem efetivamente "vestiu-se Dada" foi Elsa von Freytag-Loringhoven (1874-1927) (COSTA, 2009, p. 47). Vinculada a esse movimento, a baronesa e artista também utilizou o vestuário como forma de expressão. Trajava produtos surrupiados de grandes lojas, roupas feitas com detritos urbanos, como tampas de cerveja, e ainda chegou a usar pássaros vivos, em gaiolas, amarrados em seu pescoço. A baronesa é considerada uma das pioneiras do art-to-wear, surgido nas décadas de 1960 e 1970, ao usar o corpo e o traje como cenário e linguagem para contestar o decoro e as lógicas hegemônicas na sociedade.

Em outra perspectiva, mas também utilizando roupa como objeto artístico, vale citar o artista americano Andy Warhol (1928-1987), expoente do Pop Art, movimento que apresenta criações feitas a partir da publicidade e de outros elementos do cotidiano

\footnotetext{
3 “Duchamp inventara o termo 'readymade' para descrever os objetos fabricados em série que ele escoThia, comprava e, a seguir, designava como obras de arte” (ARCHER, 2005, p. 3).

${ }^{4}$ Pseudônimo utilizado por Marchel Duchamp para ocultar sua identidade em alguns concursos de arte dos quais participava.
} 
(ARCHER, 2005). A moda, naquele contexto, abraçava a lógica pop e o vestuário tornou-se uma importante ferramenta de divulgação desse movimento. Warhol, por exemplo, criou um vestido de papel (The Souper Dress - 1966) estampado com os rótulos das latas de sopa de tomate Campbell's, considerada ícone do cotidiano americano e da cultura de consumo daquela época.

A partir da década de 1960, a veste aparece cada vez mais em proposições artísticas. A roupa passava a ser compreendida como uma nova linguagem, um objeto de reflexão pelo campo da arte (COSTA, 2009). Alguns artistas enunciavam, por intermédio de diversos procedimentos, como o vestir, pensamentos críticos em relação à sociedade. Nessa perspectiva, este estudo destaca a artista plástica americana Andrea Zittel (1965-), que utiliza o vestuário em suas propostas.

\section{Andrea Zittel: breve panorama sobre a artista}

Andrea Zittel nasceu no sul da Califórnia (EUA), em um subúrbio da cidade de Escondido. De origem modesta, desde pequena lidava com restrições de consumo, tal como cita no documentário Consumption ${ }^{5}$, ao mencionar suas experiências em relação à sua arte.

Na década de 1990, já bacharel em Belas Artes pela San Diego State University (1988) e mestre em escultura pela Rhode Island School of Design (1990), Zittel muda-se para a Nova York e começa a trabalhar como atendente na Hearn Pat Galery6. Paralelamente, desenvolvia seus experimentos em um estúdio alocado em sua casa de $60 \mathrm{~m}^{2}$, onde compartilhava vida e trabalho. 0 lugar foi concebido como "instituto investigativo de vida, que englobando móveis, roupas e alimentos, buscou compreender melhor a natureza humana e a construção social das necessidades" (CASH, 2006, p. 126)7.

Naquela época, a artista fazia um experimento com frangos ${ }^{8} \mathrm{e}$, para abrigá-los em sua residência, criou o A-Z Breeding Unit for Averaging Eight Breeds (figura 1), que consistia em um alojamento para os animais. Para isso, a artista desenvolveu unidades de criação, como eram denominadas, utilizando estruturas de aço soldado e placas flexíveis de madeira, cujo pré-requisito era proporcionar conforto em um espaço limitado.

\footnotetext{
${ }^{5}$ Documentário veiculado em 2001 na primeira temporada da série televisiva Art in the Twenty-First Century, produzida pela organização sem fins lucrativos Art21 em parceria com o canal de televisão americana PBS. A série permite aos espectadores observarem os artistas em ação.

${ }^{6}$ Galeria de arte localizada em Chelsea (NY), do marchand Pat Hearn (1955-2000), destaque nas décadas de 1980 e 1990.

Tradução nossa para: "A-Z as an 'institute of investigative living' encompassing furniture, clothing and food, that seeks to 'better understand human nature and the social construction of needs'”.

${ }^{8}$ Parte de um experimento maior que visava reduzir oito raças de frangos a uma única ave com características mais originais da espécie, levantando questões de controle, organização e noções de progresso e criatividade (ZITTEL, 1993).
} 


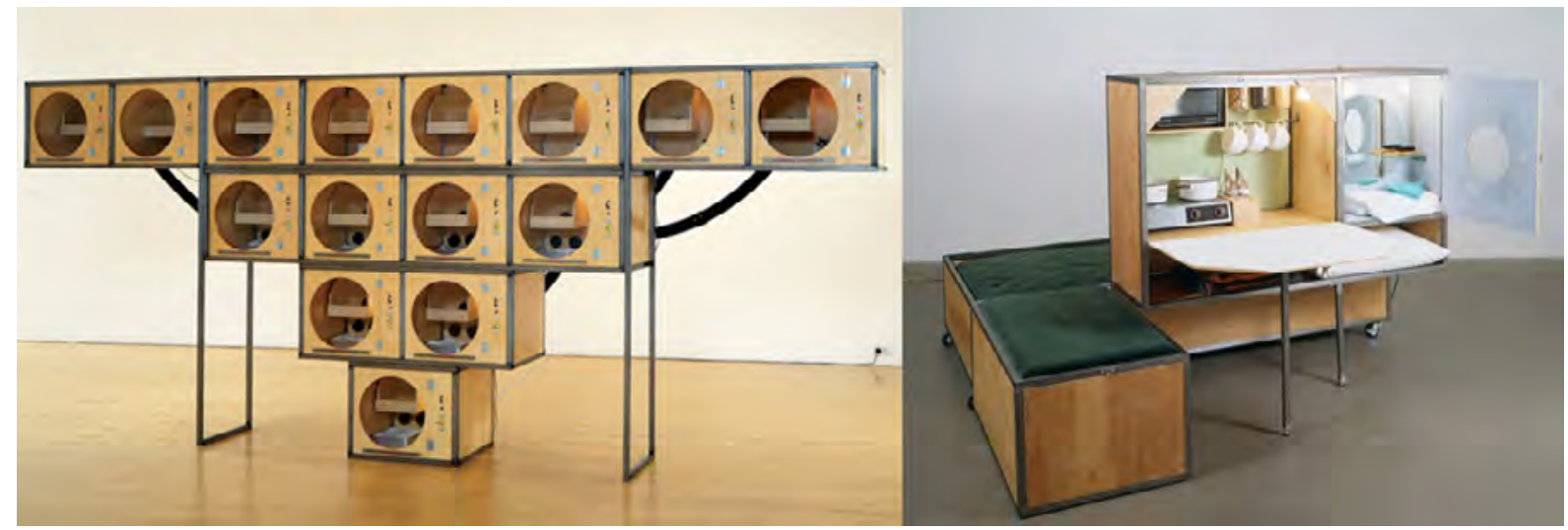

FONTE: http://www.zittel.org/work/a-z-breeding-unit-for-averaging-eight-breeds e http://www.zittel. org/work/a-z-1994-living-units. Acesso em: 4 jun. 2017. Fotos: Andrea Zittel e Thomas Stevenson. Imagem: montagem feita pelas autoras.

Esse trabalho disparou um desejo de criar estruturas chamadas pela artista de unidades de vida A-Z Living Units (figura 1), para que ela própria pudesse experimentar viver apenas com o necessário. Com o tempo, percebeu que suas práticas levavam-na a transformar sua própria vida. Sobre essa experiência, Zittel (2001) destaca que estava sendo cobaia para compreender os modos de funcionamento da sociedade como um todo.

Nos anos 2000, Andrea Zittel muda-se para um lugarejo deserto, a 225 quilômetros de Los Angeles, nomeado $A-Z$ West, onde acontecem contínuos testes que investigam o viver, "observando como estruturas e limitações muitas vezes têm a capacidade de gerar sentimentos de liberdade" (ZITTEL, 2000, s.p.) ${ }^{9}$. A-Z West comporta a casa de Zittel, um estúdio de tecelagem, o acampamento Wagon Station formado por abrigos-cápsulas para os visitantes dormirem, o campo de regeneração de materiais The Regeneration Field e o High Desert Test Sites, um local de testes para futuros projetos (ZITTEL, 2000).

A artista pontua que, quando começou a trabalhar, foi muito influenciada "[...] por noções de arquitetura e controle social, como as ideias de Foucault sobre vigilância e panóptico ${ }^{10}$. Mas, com o passar do tempo, percebeu que todos os espaços são formas de controle, de um modo ou de outro" (ZITTEL, 2017, s.p.) ${ }^{11}$. Desde então, a artista começou a propor

\footnotetext{
Tradução nossa para: "Observing how structure and limitations often have the capacity to generate feelings of freedom".

10 Com base na ideia de que estamos sendo observados e controlados - como por um panóptico (estrutura que de determinado ponto permite vigiar um todo) -, de acordo com a teoria de Michel Foucault, vista na obra Vigiar e punir (1975), o poder procura atuar por meio da vigilância, do controle e da correção do comportamento dos sujeitos.

11 Tradução nossa para: "When I first started making work I was very much influenced by notions of architecture and social control such as Foucault's ideas about surveillance and the panopticon. But since then I've realized that all spaces are spaces of control in one way or another".
} 
obras que se relacionam com outros campos, para além da arquitetura, como, por exemplo, o design de moda (MCQUILTEN, 2011).

\section{A-Z Uniforms: um trajeto pelas roupas da artista}

A relação de Andrea Zittel com o universo do design de moda deu-se em 1991, quando trabalhou na Hearn Pat Gallery e se deparou com "o dilema comum dos assistentes de galerias: vestir-se de maneira sofisticada mesmo com um salário irrisório” (CASH, 2006, p. 127 ${ }^{12}$. Viu-se constantemente pressionada a usar roupas novas e diferentes, adequadas aos códigos de vestimenta de seu trabalho. Essa situação disparou o projeto $A-Z$ Six Months Uniforms (figura 2), que consistia em vestir um único uniforme criado e costurado por ela durante uma temporada de seis meses. A própria artista descreve sua motivação:

\footnotetext{
A maioria de nós possui uma roupa favorita que sempre nos faz sentir bem, mas a etiqueta social dita que devemos usar roupas diferentes todos os dias. Às vezes, essa multiplicidade de opções pode nos fazer sentir mais restritos do que quando temos opções limitadas. Cansada da tirania da variedade constante, comecei um projeto de uniforme de seis meses. (ZITTEL, 2004, s.p.) $)^{13}$
}

Ao longo de quatro anos foram criados seis vestidos pretos (um com barra na cor cinza), duas camisas brancas, uma blusa de manga comprida listrada e uma saia preta com suspensório; todos variando entre tecidos de lã, algodão e cetim.

0 desenvolvimento das peças foi atrelado às funções que Zittel exercia e à necessidade de um uniforme flexível e funcional, adequado à galeria, mas também ao trabalho em seu estúdio, que incluía a criação dos frangos. Segundo a artista (ZITTEL, 1991, s.p.) ${ }^{14}$, usar um uniforme único por seis meses "não eliminou apenas o estresse de escolher uma roupa diária, mas também criou uma alternativa ao mandato da cultura de consumo obrigatória de caráter perpétuo", que age pressionando os sujeitos a ter que comprar e usar uma variedade de roupas.

Depois desse projeto, ela desenvolveu o Personal Panel Uniforms (1995) (figura 2), inspirado nas formas geométricas das criações de designers construtivistas russos, mantendo o estado natural da matéria-prima, apenas intervindo na criação de seus complementos. As roupas dessa segunda proposição, predominantemente geométricas, eram cortadas e costuradas em formas que respeitassem sua origem retangular e plana (MCQUILTEN, 2011).

\footnotetext{
12 Tradução nossa para: "Facing the common dilemma of gallery assistants expected to look polished and chic on a grubby salary".

13 Tradução nossa para: "Most of us own a favorite garment that always makes us look and feel good, but social etiquette dictates that we wear a different change of clothes every day. Sometimes this multitude of options can actually feel more restrictive than a self-imposed constant. Because I was tired of the tyranny of constant variety, I began a six-month uniform project".

14 Tradução nossa para: "By wearing a single uniform for six months, she not only eliminated the stress of choosing a daily outfit, but also generated an alternative to the mandate of perpetual variety mandated consumer culture".
} 
Nessa perspectiva, a artista criou e produziu cinco peças simples com a modelagem retangular dos aventais em diferentes tecidos, com poucos recortes e poucas alterações na constituição do material e suas propriedades. Algumas dessas roupas contêm bolsos funcionais e todas podem ser reguladas no pescoço e na cintura por tiras que cumprem a função de ajuste ao corpo e fechamento. As cores seguem os tons acinzentados e duas peças trazem estampas de padrão geométrico. Esses aventais “[...] enfatizam a natureza disciplinar de Zittel, reforçando a importância do trabalho, da eficiência, da regulação e da ordem na vida da artista" (MCQUILTEN, 2011, p. 68) ${ }^{15}$.

FIGURA 2 - À ESQUERDA, A-Z SIX MONTHS UNIFORMS (1991); NO CENTRO, PERSONAL PANEL UNIFORMS (1995); À DIREITA, RAUGH PERSONAL UNIFORM (1998)

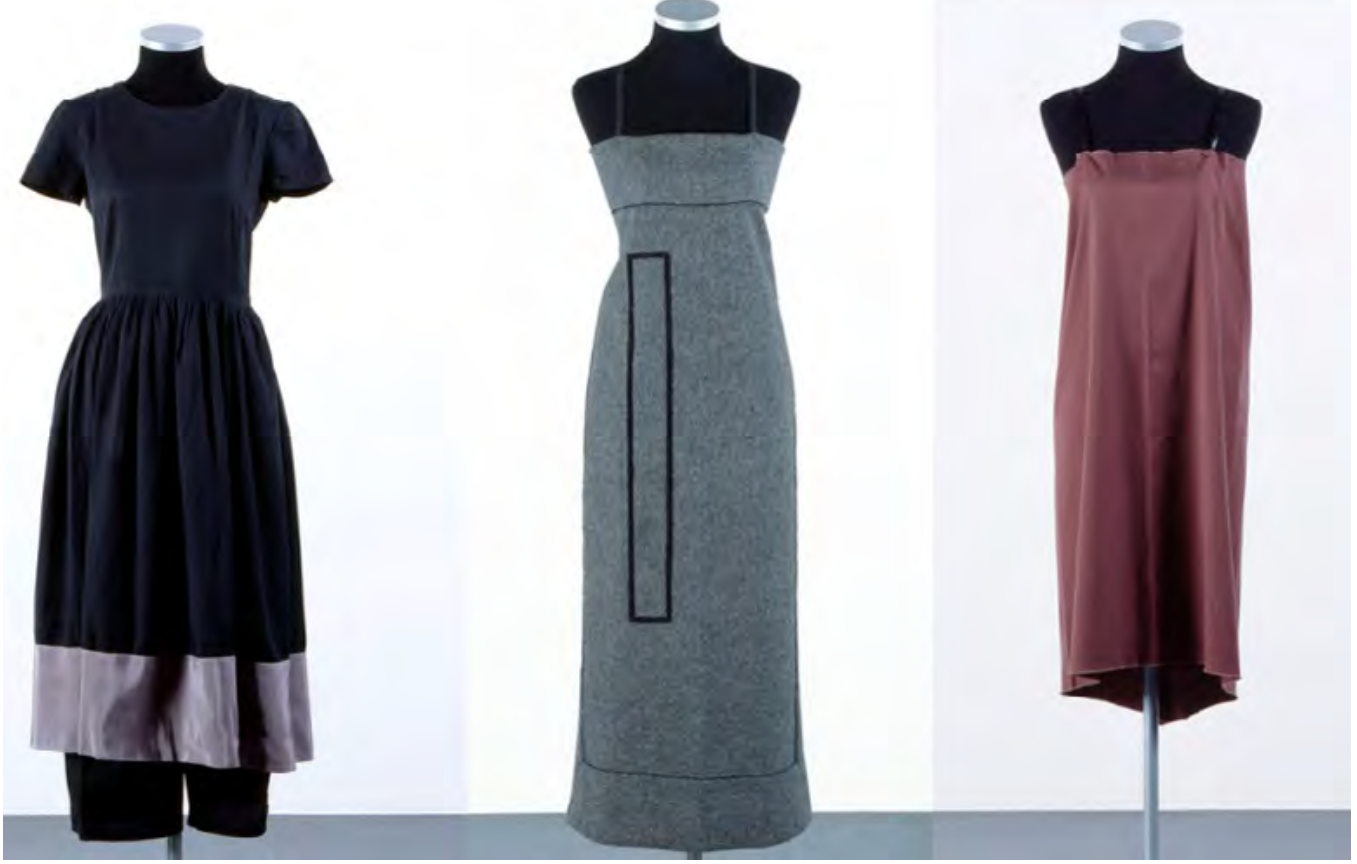

FONTE: http://www.zittel.org/work/six-month-uniforms, http://www.zittel.org/work/personal-paneluniforms e http://zittel.org/works. Acesso em: 4 jun. 2017. Fotos: Andrea Zittel e Thomas Stevenson.

Imagem: montagem feita pelas autoras.

Em 1998, Andrea Zittel reduziu ainda mais os mecanismos de desenvolvimento dessas peças ao usar apenas um tipo de pino metálico e duas alças para ajustar o tecido retangular ao corpo, intitulando o projeto de Raugh Personal Uniform (figura 2).

No mesmo ano, obstinada por desenvolver peças que exigissem o menor número de implementos possíveis, a artista criou vestidos que necessitavam apenas de fio e agulha para serem confeccionados. Desde então, começou a usar a técnica do crochê para fabricar

\footnotetext{
15 Tradução nossa para: "Emphasised the disciplinarian, totalitarian nature of A-Z, reinforcing the importance of work and efficiency, regulation and order in Zittel's life".
} 
roupas em diversas cores e com padrões aleatórios de estamparia, não utilizando tesoura para cortar os fios, mas desfazendo e arrebentando-os com as mãos, quando necessário. Esse projeto, nomeado Single Strand Uniforms (1998-2001) (figura 3) trouxe ainda mais liberdade de desenvolver um vestido “[... em qualquer hora e lugar" (ZITTEL, 2004, s.p.) ${ }^{16}$. Porém, diferentemente das peças dos outros projetos, estas eram usadas durante três meses, pois esgarçavam-se com o tempo.

Sobre o processo de crochetar as peças, Andrea Zittel menciona o receio de perder a agulha de crochê em algum momento do trabalho. Se isso acontecesse, teria que recalcular as medidas e os padrões que estavam sendo construídos, talvez precisasse recomeçar tudo. Então, considerando que cada vestido levava de seis a oito semanas de trabalho, começou a investigar maneiras de ligar os fios utilizando os dedos, ou seja, tecer as peças com seu próprio corpo. Em suas próprias palavras: "Eu gostava da pureza dessa ideia, pois me lembrava de um inseto fazendo seu próprio casulo" (ZITTEL, 2004, s.p.) ${ }^{17}$.

No fim de 2001, Zittel descobriu uma técnica simples para fazer isso, mas que exigia prática e precisão para controlar corretamente a tensão dos fios. Esse projeto ficou conhecido como Single Strand Handmade (2001) (figura 3), composto por três blusas e um vestido com padrões abstratos, semelhantes a redes irregulares, nas cores cinza, preto, marrom e bege.

\section{FIGURA 3 - À ESQUERDA, SINGLE STRAND UNIFORMS (1998-2001); NO CENTRO, SINGLE STRAND HANDMADE (2001); À DIREITA, FIBER FORM UNIFORMS (2002).}
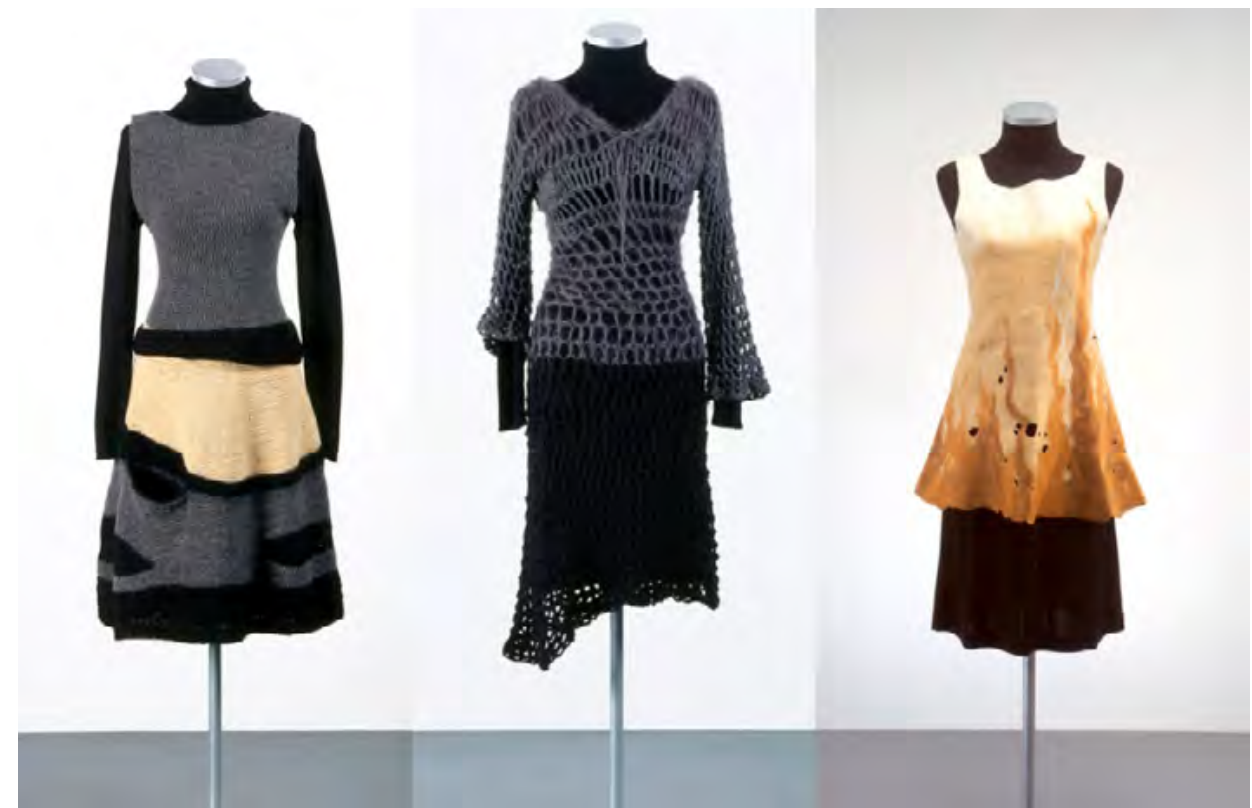

FONTE: http://zittel.org/works. Acesso em: 4 jun. 2017. Fotos: Andrea Zittel e Thomas Stevenson. Imagem: montagem feita pelas autoras.

\footnotetext{
16 Tradução nossa para: "I could create a dress anywhere, anytime".

17 Tradução nossa para: "I liked the purity of this idea, as it reminded me of an insect spinning its own cocoon, but instead I would be using my body to weave a covering for itself".
} 
Já em 2002, com intuito de testar a produção de roupas sem utilizar nenhuma costura, Zittel iniciou o projeto Fiber Form Uniforms (figura 3). A partir da técnica de feltragem ${ }^{18}$, criou blusas, túnicas e vestidos feitos com lãs prensadas e em cores terrosas. Essas peças foram produzidas em parceria com outro trabalho, intitulado A-Z Advanced Technologies, cuja ideia era unir projetos tecnológicos com "saberes pré-industriais, que remontam ideais primitivos" (ZITTEL, 2002, s.p.) ${ }^{19}$.

No ano de 2004, Andrea Zittel iniciou a segunda década do projeto original de uniforme A-Z Uniform Project Second Decade (figura 4), que durou até 2014 e reuniu roupas dos projetos apresentados anteriormente, Fiber Form Uniforms, Personal Panel Uniforms e Single Strand Uniforms, além de outros quatro vestidos nas cores marrom-claro, marrom-escuro, lilás e azul-esverdeado. Essa segunda edição visou destacar que as peças produzidas por ela, "[...] embora atraentes e funcionais, questionam nossas associações de liberdade com a demanda do mercado por variedade constante. 0 projeto Uniform propõe que a liberdade pode ser possível por meio da criação de um conjunto de restrições ou limitações pessoais" (ZITTEL, 2004b, s.p.) ${ }^{20}$.

\section{FIGURA 4 - A-Z UNIFORM PROJECT SECOND DECADE (2004-2014)}

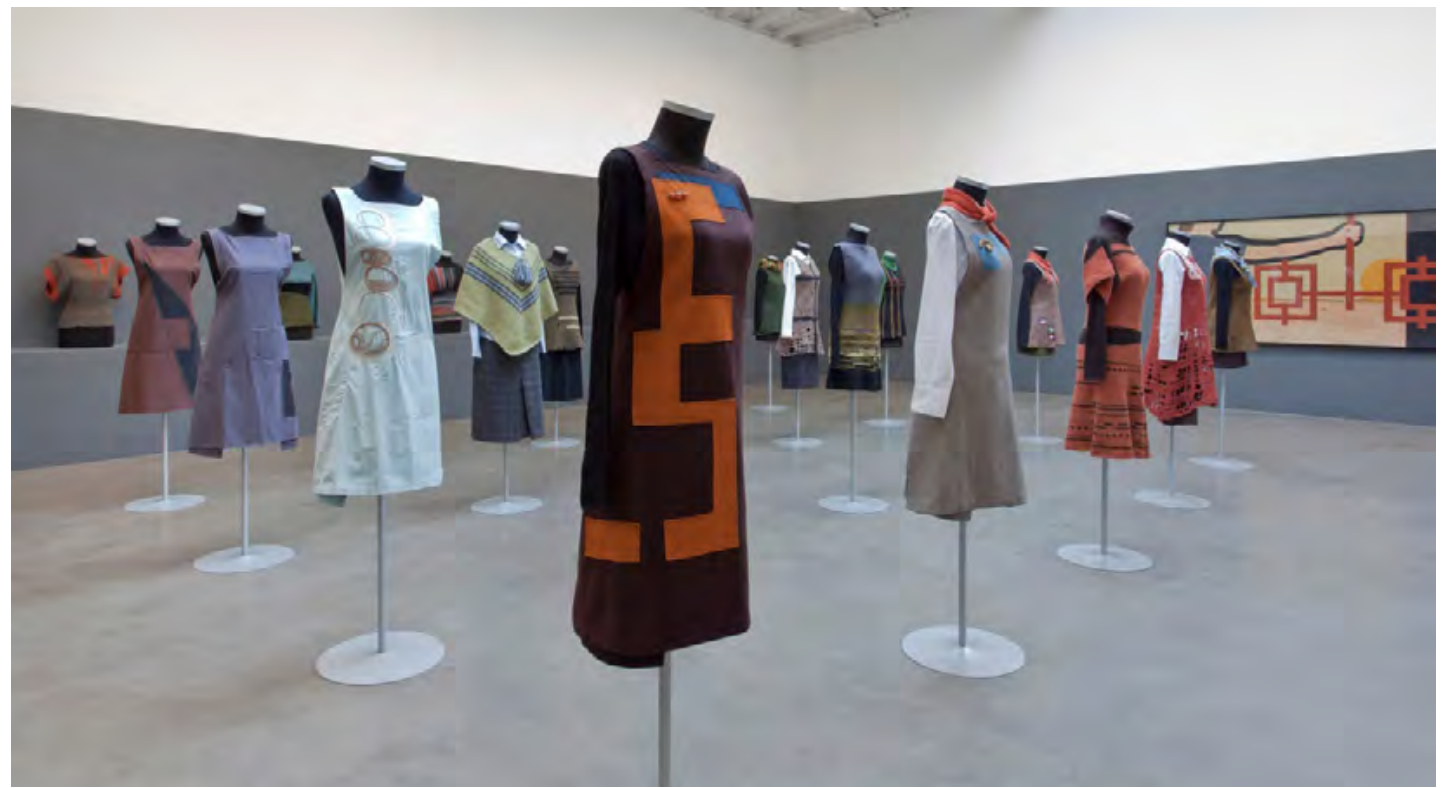

FONTE: http://www.zittel.org/work/a-z-uniform-project-second-decade. Acesso em: 4 jun. 2017.. Foto: Andrea Zittel e Thomas Stevenson.

\footnotetext{
${ }^{18}$ A técnica de feltragem visa formar "tecidos não tecidos", ou seja, compacta as fibras têxteis sem precisar tecê-las.

19 Tradução nossa para: "Bringing complexity of form together with pre-industrial know-how".

20 Tradução nossa para: "These garments, while both attractive and functional, question our associations of freedom or personal liberation with the market demand for constant variety. The Uniform project proposes that liberation may in fact, also be possible through the creation of a set of personal restrictions or limitations".
} 
Em 2018, esse conjunto de obras era composto por mais de setenta variações de uniformes que já foram expostos em galerias, como a Andrea Rosen Gallery ${ }^{21}$. A exposição $A-Z$ Uniforms ocorreu em 2004 e apresentou peças produzidas entre os anos de 1991 e 2002. Na ocasião, Zittel afirmou que "vestir a arte como um processo diário é uma decisão sutil, mas forte" (ZITTEL, 2014, s.p.) ${ }^{22}$ que nos remete ao cotidiano, ao corpo, aos hábitos e aos modos de vida relativos à veste.

\section{Linhas de força no dispositivo moda}

A segunda metade do século XX traz uma série de mudanças no contexto político-econômico-social mundial, revelando uma atmosfera tomada por propostas neoliberais, em que o mercado é quem dita as regras (FOUCAULT, 1979). Nesse cenário, Lipovestky (2007) observa uma sociedade pautada pelo hiperconsumo, na qual a produção de modos de vida é operada também pela lógica de consumir. Como o autor destaca, essa dinâmica de consumo vai além da utilidade e funcionalidade dos objetos, baseia-se principalmente na ordem subjetiva das mercadorias tendo em vista que essas são desejadas por vincularem os consumidores a determinados estilos de vida.

Com efeito, a moda ganhou ainda mais força na construção das subjetividades, visto que os sujeitos, amparados na busca ou no reforço da constituição de si, consomem valores simbólicos convertidos em roupas (SVENDSEN, 2010). Ainda nas palavras desse autor,

Procuramos identidade no corpo, e as roupas são uma continuação imediata dele [...] as roupas reescrevem o corpo, dão-lhe uma forma e uma expressão diferente [...] nossa percepção do corpo humano é sempre dependente das modas dominantes na época, e nossa percepção das modas é por sua vez dependente de como são representadas. (SVENDSEN, 2010, p. 87)

Nessa dinâmica, ocorre o reforço do desejo pelas novidades, por vezes provocando uma caducidade das vestes no espaço temporal, fator que demarca a efemeridade como princípio de instauração da moda desde a Modernidade (LIPOVETSKY, 2007). Porém, no universo do hiperconsumo, no qual o "desejo de moda” ultrapassou a esfera da indumentária, vê-se que o gosto pelas novidades ganhou outros aspectos. Mesquita (2008) pontua o conceito "império do estilo", entendendo que, para além do princípio de variabilidade dos produtos, é o próprio sujeito que se coloca sob o imperativo da variação de si mesmo.

Nessa lógica, o mercado da moda incrementa ainda mais a produção de novidades que articulem estilos e formas de diferenciação de si. Assim, a velocidade de consumir cada vez mais é fortalecida e renovada pelo dispositivo moda que retroalimenta a produção de subjetividade.

\footnotetext{
${ }^{21}$ Galeria de arte fundada em janeiro de 1990, localizada em Nova York (EUA).

22 Tradução nossa para: "Wearing art as a daily process is a subtle yet strong decision".
} 
Portanto, no contexto do mercado da moda, é possível ressaltar o consumismo, a efemeridade e os padrões dominantes do vestir como linhas de forças articuladoras no dispositivo moda. Neste estudo, essas linhas são ilustradas por dois exemplos. Um deles data de 1991, mesmo ano em que Andrea Zittel dispara o primeiro projeto de uniforme, o $A-Z$ Six Months Uniforms. 0 segundo exemplo data de 2018. Levando em conta que o projeto de Zittel se inicia na década de 1990 e adentra o século XXI, consideramos que os dois exemplos são pertinentes para nossa abordagem, pois ressoam neles as linhas anteriormente mencionadas.

Na edição de agosto de 1991, a revista Vogue americana (figura 5) estampa sua capa com a modelo holandesa Karen Mulder. Trajando calça jeans, camisa branca sobreposta por um casaco bege, além de acessórios dourados, boné e um xale, Mulder ilustra a indicação para "estar na moda" naquele momento.

\section{FIGURA 5 - CAPA DA REVISTA VOGUE AMERICANA DE AGOSTO DE 1991}

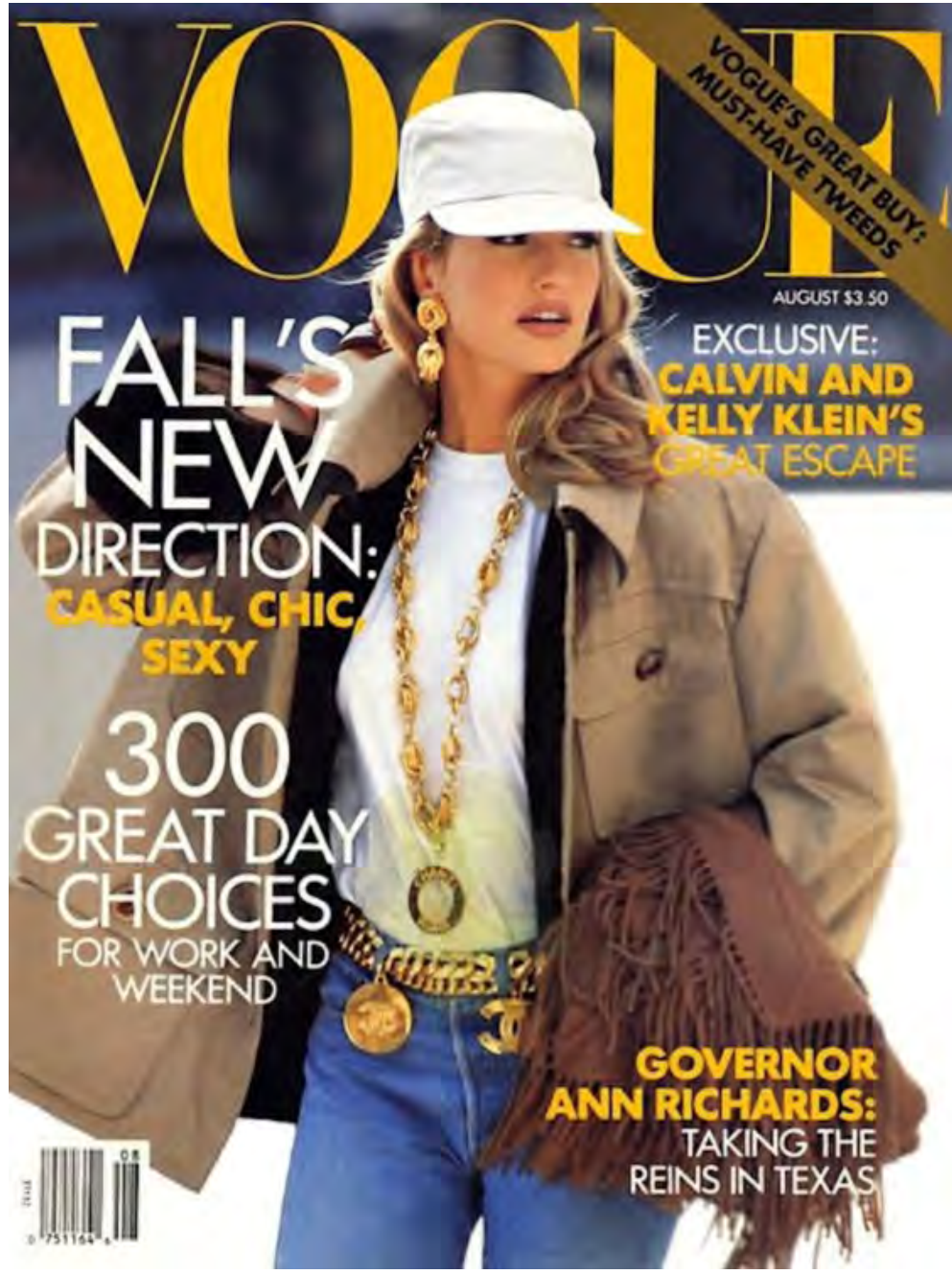

FONTE: http://www.ephemeraforever.com/vogue-august-1991. Acesso em: 10 abr. 2018.

Foto da capa: Patrick Demarchlier. 
A chamada Fall's new direction: casual, chic, sexy ${ }^{23}$ anuncia que a revista trará novidades da moda de outono, propondo as direções que o leitor deverá seguir naquela estação. Indica o que o consumidor deve adotar e define três estereótipos aceitáveis. Essa linha de força opera produzindo regras do vestir.

O mesmo enunciado, ao tratar das novidades que dominarão a estação de outono, insinua que a moda vigente na temporada anterior já não vigora mais, pois cedeu lugar ao novo. Apontando assim para a efemeridade, mecanismo vital do dispositivo moda, junto da lógica da novidade que é marca das variações constantes.

Vale mencionar que as revistas são plataformas que servem ao mercado de moda com vistas a estimular o consumo, adotando discursos que promovem as novidades incessantes e a proposição de determinadas regras para o vestir. Levando em consideração os enunciados sobre as regras e novidades apresentados anteriormente, pode-se dizer que o trabalho de Zittel questiona essas linhas de força do dispositivo moda, visto que não as considera na prática do vestir. A artista prioriza a funcionalidade da roupa em detrimento dos fatores simbólicos.

Retomando a capa da revista Vogue em questão, o título 300 great day choices for work and weekend indica que a publicação apresenta trezentas opções de roupas para serem usadas durante o dia, em ocasiões de trabalho e nos fins de semana. Diante das numerosas sugestões, variar as peças desponta nas entrelinhas como um certo tipo de orientação ao leitor. Leva a crer que a diversidade de opções indica liberdade de escolha. Mas vale mencionar que essa liberdade é limitada às opções indicadas pela publicação para as duas ocasiões preestabelecidas no enunciado - trabalho e fim de semana -, fato que reitera a lógica das regras que dominam o campo do vestuário no dispositivo moda.

A suposta liberdade de cada um criar a sua própria aparência é paradoxal ao observar diversos manuais de estilo, como os livros Socorro! Com que roupa eu vou? Um guia de dress code ilustrado (2017) e Harper's Bazaar fashion: your guide to personal style (2010). Esses são apenas alguns exemplares disponíveis nas prateleiras de autoajuda das livrarias.

Vale dizer que na era do compartilhamento digital, as indicações de como se vestir não ficam mais restritas às publicações de revistas e livros. Também podem ser encontradas cada vez mais no meio virtual, como exemplo da rede social da digital influencer ${ }^{24}$ brasileira $^{2}$ Thássia Naves (figura 6).

\footnotetext{
23 A nova direção do outono: casual, chique, sexy (tradução nossa).

${ }^{24}$ Os influenciadores digitais são líderes de opinião, prescritores de tendências, com importância primordial para o atual sistema da moda. ALMADA, Larissa. Blogs: atores sociais na disseminação da cultura de moda. 2015. 120 f. Dissertação (Mestrado em Design de Comunicação de Moda), Universidade do Minho, Portugal, 2015. Disponível em: https://repositorium.sdum.uminho.pt/bitstream/1822/40235/1/Larissa Almada Neves Aprigio.pdf. Acesso em: 15 maio 2018.
} 


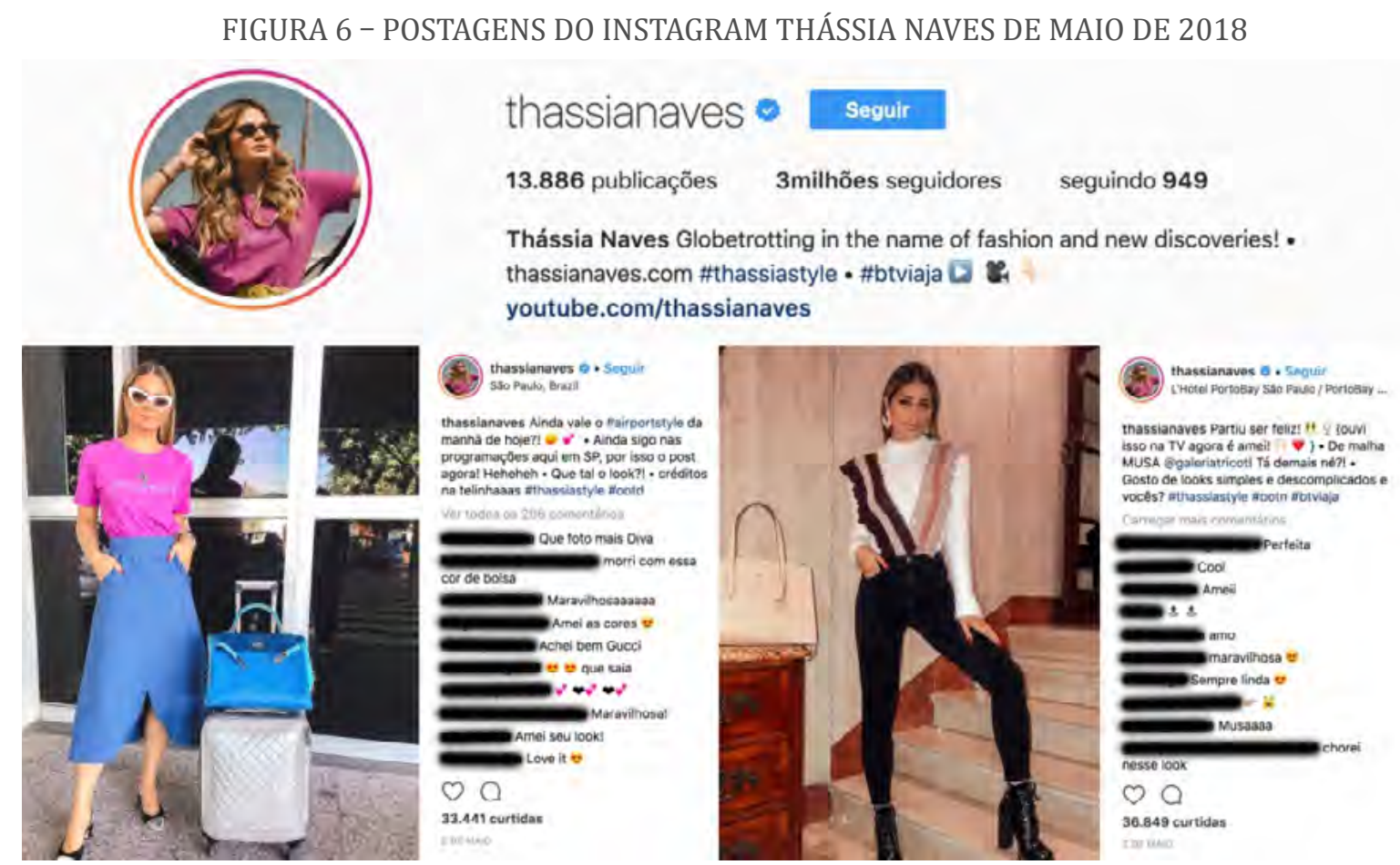

FONTE: https://www.instagram.com/thassianaves. Acesso em: 2 maio 2018. Imagem: montagem das autoras mediante print de tela da rede social.

Com 3 milhões de seguidores e 13.886 publicações ${ }^{25}$ desde 2013, Thássia expõe o que usa diariamente. Na postagem do dia 2 de maio de 2018, compartilhou com os leitores o outfit ${ }^{26}$ que usou pela manhã e o do período da noite (figura 6). Sugere com isso a necessidade de ter variadas peças, além de também enfatizar que cada ocasião exige uma roupa diferente; a repetição de itens não é bem vista por essa lógica. Por fim, vale mencionar que Thássia marca ${ }^{27}$ as fotos de seu outfit of the day, como é chamado o visual usado no dia, com a hashtag ${ }^{28}$ \#ootd, uma das mais usadas mundialmente, com 186.342 .489 publicações, ainda atrás da hashtag \#fashion, a quarta mais usada nessa rede social ${ }^{29}$.

\footnotetext{
25 Disponível em: www.instagram.com/thassianaves. Acesso em: 20 maio 2017.

26 Conjunto de peças do vestuário.

27 Marcar as imagens na internet com hashtags serve para organizar informações, agrupando aquelas que receberam a mesma marcação.

28 Etiquetas digitais usadas em ambiente virtual.

${ }^{29}$ Com o total de 516.392.659 publicações, fica abaixo de hashtags como \#photooftheday, \#instagood e \#love, terceira, segunda e primeira posições respectivamente. Disponível em: https://top-hashtags.com/instagram/. Acesso em: 20 maio 2017.
} 


\section{Considerações finais}

Quando em diálogo com o cotidiano, a arte contemporânea promove questionamentos que enfatizam as relações entre arte e vida e podem problematizar os modos de vida hegemônicos. A utilização de objetos não usuais da arte, como o vestuário, é adotada como um dos modos de operar essas provocações. Nesse contexto, os projetos Uniforms, da artista Andrea Zittel, emergem como ferramentas capazes de questionar o dispositivo moda, visto que contrapõem os padrões engendrados.

Desde sua primeira proposição, Zittel parece seguir o caminho que diverge das demandas desse dispositivo. A variedade e o consumismo são colocados em questão pelo uso de uma quantidade limitada de roupas, configuradas para serem uniformes durante temporadas. Nesse sentido, supõe-se que os uniformes atuam, inclusive, aliviando uma certa pressão da escolha do que vestir diariamente, ou mais vezes no dia, no contexto em que numerosas peças encontram-se disponíveis. Vale lembrar que o mercado de moda estimula o consumo de diversas maneiras, uma delas é a periodicidade de revistas que apresentam novos produtos e formas de usá-los, promovendo as novidades em cada estação climática do ano, em cada modismo ligado ao contexto sociocultural ou em divulgações diárias em redes sociais.

Não apenas o mercado, mas a própria engrenagem de produção do dispositivo moda é, de alguma maneira, questionada quando observamos esses projetos da artista. Confeccionar seu próprio vestuário, de modo autônomo, em vez de comprar roupas prontas, comercializadas em larga escala, pode ser uma maneira de resistir. Produzir as peças de modo manual, com poucas ferramentas, o que pressupõe tempo maior de produção, coloca em jogo a lógica rápida de fabricar produtos, pois os uniformes demoram para ficar totalmente prontos.

As linhas de força, que de alguma forma impõem o que se deve vestir em determinadas ocasiões, como sugestionam revistas, manuais de estilo e influenciadores digitais, aparecem enfraquecidas no contexto de Zittel. 0 fato de a artista escolher o que irá utilizar baseando-se nas necessidades práticas do cotidiano, como o uso de calças para cuidar das galinhas, pode ser percebido como uma ruptura ao que é imposto, visto que Zittel se atém aos aspectos funcionais das peças e não aos simbolismos tramados no dispositivo moda.

Por fim, considera-se que as criações da artista Andrea Zittel são linhas de resistência ao efeito hegemônico produzido pelas linhas de forças do dispositivo moda. Contrariam os padrões dominantes do vestir, o consumismo e a lógica do efêmero engendrados nesse dispositivo, desafiando-o ao propor outros modos de lidar com a vestimenta que podem apresentar perspectivas divergentes na produção de subjetividade. 


\section{Referências}

ALMADA, Larissa; MESQUITA, Cristiane. Design de moda: dispositivo de processos de subjetivação contemporânea. In: Colóquio de Moda, 13., Bauru, 2017. Bauru: Universidade Estadual Paulista - UNESP, 2017.

ARCHER, Michael. Arte contemporânea: uma história concisa. São Paulo: Martins Fontes, 2005.

BRANDÃO, Ludmila. Aspectos de uma estética deleuziana. Arquitextos. São Paulo: Vitruvius, 2000. Disponível em: http://vitruvius.com.br/revistas/read/arquitextos/01.005/973. Acesso em: 16 mai. 2018.

CANTON, Katia. Do moderno ao contemporâneo. São Paulo: Martins Fontes, 2009.

CASH, Stephanie. AZ and everything in between. Art in American. Nova York: Art Media Holdings, 2006, p. 124-131.

CONSUMPTION. Art in the Twenty-First Century. Produção: Ian Foster. Califórnia: Art21, 2001. Disponível em: https://art21.org/series/art-in-the-twenty-first-century/about/. Acesso em: 11 abr. 2018.

COSTA, Cacilda. Roupa de artista: o vestuário na obra de arte. São Paulo: EDUSP, 2009.

DELEUZE, Gilles. ¿Que és um dispositivo? Trad. Wanderson Flor do Nascimento. In: Michel Foucault, filósofo. Barcelona: Gedisa, 1990, p. 155-161.

FOUCAULT, Michel. Microfísica do poder. Rio de Janeiro: Edições Graal, 1979.

LIPOVETSKY, Gilles. 0 império do efêmero: a moda e seu destino nas sociedades modernas. São Paulo: Companhia das Letras, 1989.

LIPOVETSKY, Gilles. A felicidade paradoxal: ensaio sobre a sociedade de hiperconsumo. São Paulo: Companhia das Letras, 2007.

MCQUILTEN, Grace. Art in consumer: Mis-Design. Nova York: Routledge, 2011.

MESQUITA, Cristiane. Políticas do vestir: recortes em viés (Tese de doutorado). São Paulo: PUC-SP, 2008.

SVENDSEN, Lars. Moda: uma filosofia. Rio de Janeiro, Brasil: Zahar, 2010.

ZITTEL, Andrea. Works. Disponível em: http://www.zittel.org/work/six-month-uniforms. Acesso em: 4 jun. 2017. 
ZITTEL, Andrea. Six Months Uniforms. 1991. Disponível em: http://www.zittel.org/work/ six-month-uniforms. Acesso em: 4 jun. 2017.

ZITTEL, Andrea. A-Z Breeding unit for averaging eight breeds. 1993. Disponível em: http://www.zittel.org/work/a-z-breeding-unit-for-averaging-eight-breeds. Acesso em: 4 jun. 2017.

ZITTEL, Andrea. Personal Panel Uniforms. 1995. Disponível em: http://www.zittel.org/ work/personal-panel-uniforms. Acesso em: 4 jun. 2017.

ZITTEL, Andrea. A-Z West. 2000. Disponível em: http://www.zittel.org/work/a-z-west. Acesso em: 5 abr. 2018.

ZITTEL, Andrea. Consumption. Art in the Twenty-First Century. Dir. Susan Sollins e Susan Dowling. Nova York, 2001. Disponível em: https://art21.org/watch/art-in-the-twenty-firstcentury/s1/consumption/. Acesso em: 25 abr. 2018.

ZITTEL, Andrea. Fiber Form Uniforms. 2002. Disponível em: http://www.zittel.org/work/ fiber-form-uniforms. Acesso em: 4 jun. 2017.

ZITTEL, Andrea. A-Z Uniforms 1991-2002. Nova York: . Andrea Rosen Gallery, 2004. Disponível em: http://www.andrearosengallery.com/exhibitions/andrea-zittel_2004-01-22. Acesso em: 4 jun. 2017.

ZITTEL, Andrea. A-Z Uniform Project Second Decade. 2004b. Disponível em: http://www. zittel.org/work/a-z-uniform-project-second-decade. Acesso em: 4 jun. 2017.

ZITTEL, Andrea. Materials for Living. Textile Arts Center. Estados Unidos, 2014. Entrevistador: Kathleen. Disponível em: http://textileartscenter.com/blog/materials-forliving-andrea-zittel. Acesso em: 4 jun. 2017.

ZITTEL, Andrea. The alternative community of Andrea Zittel. Número. Paris, 2017. Entrevistador: Nicolas Trembley. Disponível em: http://www.numero.com/en/art/andrea-zittel-california-a-zwest-planar-pavillions. Acesso em: 4 jun. 2017. 